\title{
SISTEM INFORMASI AKUNTANSI DALAM MENUNJANG PENENTUAN HARGA POKOK PRODUKSI BERBASIS CLIENT SERVER
}

\author{
Sri Wahyuning \\ Komputerisasi Akuntansi STEKOM Semarang \\ wahyuning@stekom.ac.id
}

\begin{abstract}
Accounting information systems are needed by companies, because they help a lot, in the effectiveness and efficiency of business problems. Determination and calculation of cost of production is a very important thing to know the production costs incurred as well as the benefits to be obtained. PT. Barokah Sejahtera is a company engaged in wall paint products, where in its products depends on the policy of determining and calculating factory overhead costs, if factory overhead costs are the dominant cost, then allocation based on volume will cause errors in determining cost of production by calculating the overall cost raw materials issued with products produced during the production process. In addition, the process of recording and calculation requires considerable time which results in difficulties in analyzing profits. To overcome these problems, the application of Activity Based Costing System and Client Server based methods is carried out. All activities are intended to produce products with adequate costs. The main focus of company management on activity management, namely planning and controlling all company activities in producing products with the appropriate cost level. The research method used is the RND method / Reset and Development Accounting information system calculation of the cost of production is expected to be applied to the company so that it can be more effective and efficient in calculating the cost of production
\end{abstract}

Keywords : Systems; Accounting; Activity Based Costing; RND

\section{Pendahuluan}

Penggunaan Teknologi informasi sangat membantu sebuah organisasi bisnis untuk mengembangkan diri dan mewujudkan sasaran usahanya. Peran sistem informasi akuntansi yang dimiliki oleh organisasi bisnis tersebut diharapkan dapat meningkatkan kualitas dan produktivitas sehingga proses kegiatan produksi menjadi efektif dan efisien. Perhitungan harga pokok produksi pada kegiatan produksi merupakan salah satu hal yang sangat penting. Keakuratan perhitungan harga pokok produksi menghasilkan laporan harga pokok produksi yang akurat. Perusahaan manufaktur yang merupakan perusahaan yang bergerak dalam bidang pengolahan bahan mentah menjadi barang jadi, mempunyai daya saing tersendiri dalam lingkup bisnisnya. Proses produksi memegang peran yang sangat besar terhadap kesuksesan perusahaan itu dalam menapaki dunia usahanya. Untuk itu hal yang terpenting adalah bagaimana perusahaan mampu melakukan perhitungan harga pokok produksi yang mampu membantu dalam pengelolaan data yang bersifat terus menerus, punya ketelitian dan kecepatan proses yang tinggi, dan kapasitas penyimpan data yang memadai sehingga lebih efisien terhadap biaya, waktu dan tenaga. Apabila perhitungan harga pokok produksi kurang tepat dalam perhitungannya, maka yang akan terjadi harga barang produksi yang terlalu mahal sehingga produk tidak dminati konsumen, sebaliknya apabila harga terlalu rendah memang akan menarik minat konsumen untuk membeli produk hasil produksi perusahaan, namun hal ini menyebabkan hasil penjualan tidak dapat menutup biaya produksi. Apabila keadaan ini terus berlanjut, maka dapat menyebabkan kerugian pada perusahaan tersebut. Keputusan untuk membuat perencanaan produksi sebagai dasar dalam memulai produksi seperti banyak jumlah bahan baku yang akan dibutuhkan, komponen biaya yang akan timbul, perkiraan waktu pelaksanaan kegiatan produksi. Pengendalian biaya produksi seperti biaya tenaga kerja, biaya bahan baku dan biaya overhead, serta perhitungan harga pokok produksi yang tepat sangat dibutuhkan karena akan mempengaruhi harga jual produk. Komponen pembentukan laba merupakan pendapatan yang diperoleh dari hasil penjualan produksi dan jasa yang dihasilkan oleh perusahaan.

Dari permasalahan diatas dan pentingnya penentuan harga pokok produksi yang digunakan untuk menentukan harga jual produk serta penentuan harga persediaan produk jadi dan produk dalam proses yang akan dijadikan dalam neraca maka penerapan metode Activity Based Costing sangat membantu dalam permaslahan ini, ditambahkan adanya penerapan Client server yang saling terintegrasi kesemua user. Hal inilah yang diharapkan oleh PT. Barokah Sejahtera untuk dapat memberikan penentuan harga pokok produksi secara efektif dan efisien. 


\section{Identifikasi Masalah}

Kelemahan sistem lama dalam penentuan dan perhitungan ini adalah pada pembebanan biaya overhead. Dalam sistem akuntansi biaya tradisional, biaya overhead dialokasikan ke produk berdasarkan volume produk yang yang dilakukan dengan cara sembarang (tanpa perhitungan) Dasar yang biasa digunakan adalah volume unit produksi, jam kerja langsung, jam mesin, dan yang menjadi masalah adalah jika biaya overhead pabrik merupakan biaya dominan, maka alokasi berdasarkan volume akan menimbulkan kekeliruan dalam penetapan harga pokok produksi.

Oleh karena itu, diperlukan alternaif perhitungan harga pokok produksi yang mempunyai, perhatian terhadap aktivitas, yaitu Activity Based Costing System (ABC SYSTEM).. Activity Based Costing System menghasilkan informasi yang dapat membatasi distorsi dan subsidi silang yang disebabkan oleh pengalokasian sistem akuntansi tradisional. Penghematan biaya dapat dilakukan dengan membatasi aktivitas - aktivitas tidak menambah nilai. Dengan demikian dapat digunakan sebagai dasar untuk perbaikan profitabilitas perusahaan, sehingga keunggulan perusahaan dapat diraih.

Dengan menggunakan system informasi akuntansi berbasis komputer yaitu dengan menggunakan bahasa pemrograman visual basic, user akan lebih mudah untuk proses input dan output data. Memudahkan dalam informasi harga pokok produksi sehingga pelaporan informasi kepada pihak manajemen akan lebih efektif dan efisien

\section{Tujuan Penelitian}

1. Menghasilkan suatu sistem informasi akuntansi berbasis komputer yang valid untuk menghitung harga pokok produksi sehingga kesulitan dalam mengetahui laba / rugi kotor dari setiap produksi dapat teratasi dengan metode activity based costing.

2. Memperoleh efektifitas sistem informasi akuntansi berbasis komputer atas penentuan harga pokok produksi yang jauh lebih efektif. Pada perhitungan harga dan penyampaian laporan keuangan

\section{Landasan Teori}

\subsection{Sistem Informasi Akuntansi}

Susunan berbagai formulir catatan, peralatan, termasuk komputer dan perlengkapan serta alat komunikasi, tenaga pelaksananya dan laporan yang terkoordinasikan secara erat yang didesain untuk mentransformasikan data keuangan menjadi informasi keuangan yang dibutuhkan manajemen. Nugroho Widjayanto (2001:4)

\subsection{Sistem Akuntansi Terkomputerisasi.,}

Pprogram-program yang digunakan dalam menjalankan siklus akuntansi, seperti penjurnalan, posting (pembukuan) dan penyususunan neraca saldo. Dalam sistem yang terkomputerisasi, jurnal dan buku besar dapat dicatat dalam basis data (database) komputer. Lebih jauh lagi, telah ada software untuk menjalankan sistem bisnis seperti fungsi penagihan, fungsi penyiapan penggajian dan fungsi penganggaran. Weygant dkk;2014:398)

\subsection{Client Server}

Server adalah komputer database yang berada di pusat, dimana informasinya dapat digunakan bersama-sama oleh beberapa user yang menjalankan aplikasi di dalam komputer lokalnya yang disebut dengan Client. Budhi irawan (2005:30)

\subsection{Microsoft Visual Basic}

bahasa pemrograman generasi ke tiga dari Microsoft dengan IDE (Integrated Development Environment) atau pemrograman pengembangan terpadu, visual basic dibuat dan dirancang untuk mudah digunakan baik oleh programmer pemula sekalipun (Atmoko, 2013).

\subsection{Basis Data (Database)}

Menurut C.J. Date (2007) mengatakan bahwa sistem basis data pada dasarnya dapat dianggap sebagai tempat atau lokasi untuk sekumpulan berkas data yang sudah terkomputerisasi dengan tujusab untuk memelihara informasi, dan juga memuat informasi tersebut, terutama apabila informasi tersebut sedang dibutuhkan.

\subsection{Sistem Activity Based Costing}

Menurut Armanto Witjaksono (2006 : 207-218) sejalan dengan makin meningkatnya kompetisi dalam dunia usaha, para pelaku usaha terutama manajer sebagai pengambil keputusan meminta para akuntan untuk dapat mengaitkan biaya (cost) dengan suatu aktivitas atas dasar sebab akibat (casual). Hal ini kemudian pada gilirannya menyebabkan perkembangan activity based costing $(\mathrm{ABC})$, yang juga dikenal dengan istilah transaction based costing.

\subsection{Konsep Dasar Sistem Activity Based Costing} Sistem ABC dapat memberikan informasi mengenai aktivitas-aktivitas dan biayanya. Mengetahui aktivitas-aktivitas apa yang dilakukan dan biaya-biayanya memungkinkan manajer memusatkan perhatiannya pada aktivitas-aktivitas yang dapat membuat peluang terhadap penghematan biaya.

Ada dua keyakinan dasar yang melandasi sistem biaya activity based costing menurut Mulyadi (2007:803) yaitu :

\section{Cost in caused}

Biaya ada penyebabnya dan penyebab biaya adalah aktivitas, sistem activity based costingberangkat 
dari keyakinan dasar bahwa sumber daya menyediakan kemampuan untuk melaksanakan aktivitas, bukan sekedar menyebabkan timbulnya biaya yang harus dialokasikan.

2. The cause of cost can be managed

Penyebab terjadinya biaya yaitu aktivitas dapat dikelola.Melalui pengelolaan terhadap aktivitas yang menjadi penyebab terjadinya biaya, personal perusahaan dapat mempengaruhi biaya.Pengelolaan terhadap aktivitas memerlukan berbagai informasi tentang aktivitas.

Pada konsep ini dasar activity based costingtersebut, biaya yang merupakan konsumsi sumber daya (seperti bahan, energi, tenaga kerja, dan modal) dihubungkan dengan aktivias yang mengkonsumsi sumber daya tersebut. Dengan demikian melalui pengelolaan aktivitas dengan baik menghasilkan keunggulan ko mpetitif dalam jangka panjang.

\subsection{Manfaat Penerapan Activity-Based Costing} System

Manfaat penerapan sistem Activity-Based Costing menurut Dunia dan Abdullah (2012:328), sebagai

berikut:

1. Membantu mengidentifikasi ketidakefisienan yang terjadi dalam proses produksi, baik per departemen, per produk ataupun per aktivitas.

2. Membantu pengambilan keputusan dengan lebih baik karena perhitungan biaya atas suatu objek biaya menjadi lebih akurat.

3. Membantu mengendalikan biaya (terutama biaya overhead pabrik) kepada level individual dan level departemental.

\section{Metode Penelitian}

3.1 Penelitian dan Pengembangan (R\&D)

Sedangkan Borg and Gall (1983:772) mendefinisikan penelitian pengembangan sebagai proses yang digunakan untuk mengembangkan dan memvalidasi produk pendidikan. Langkah-langkah dari proses ini biasanya disebut sebagai siklus R\&D, yang terdiri dari mempelajari temuan penelitian yang berkaitan dengan produk yang akan dikembangkan, mengembangkan produk berdasarkan temuan ini, bidang pengujian dalam pengaturan di mana ia akan digunakan akhirnya , dan merevisinya untuk memperbaiki kekurangan yang ditemukan dalam tahap mengajukan pengujian. Dalam program yang lebih ketat dari R\&D, siklus ini diulang sampai bidang-data uji menunjukkan bahwa produk tersebut memenuhi tujuan perilaku didefinisikan.

\subsection{Prosedur Pengembangan}

Dalam penelitian ini prosedur yang digunakan mengacu pada penelitian research and development dan rancangan penelitian pengembangan ini dapat dilihat pada gambar 3.1 yang menerangkan sebagai berikut:

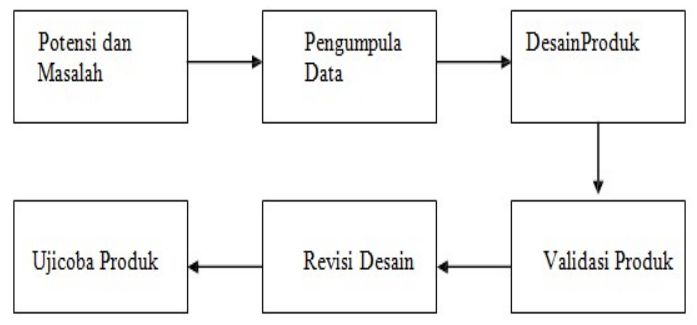

Gambar 3.1 Pengembangan Penelitian R\&D ( Sumber : Sugiyon, 2008)

3.3 Teknik Analisis Data

Teknik analisis yang digunakan dalam penelitian ini adalah sebagai berikut.

1. Melakukan perhitungan harga pokok produksi dengan sistem tradisional.

2. Melakukan perhitungan harga pokok produksi dengan Metode Activity Based Costing.

3. Melakukan perbandingan antara perhitungan harga pokok produksi perusahaan dengan sistem tradisional dengan Metode Activity Based Costing.

\subsection{Kerangka Berfikir}

Kerangka berfikir merupakan sintesa tentang bungan antara variabel yang disusun dari berbagai teori yang telah dideskrpsikan. Sugiyono (2012: 89) Seperti halnya pada gambar 3.2 yang menjelaskan Kerangka Berfikir.

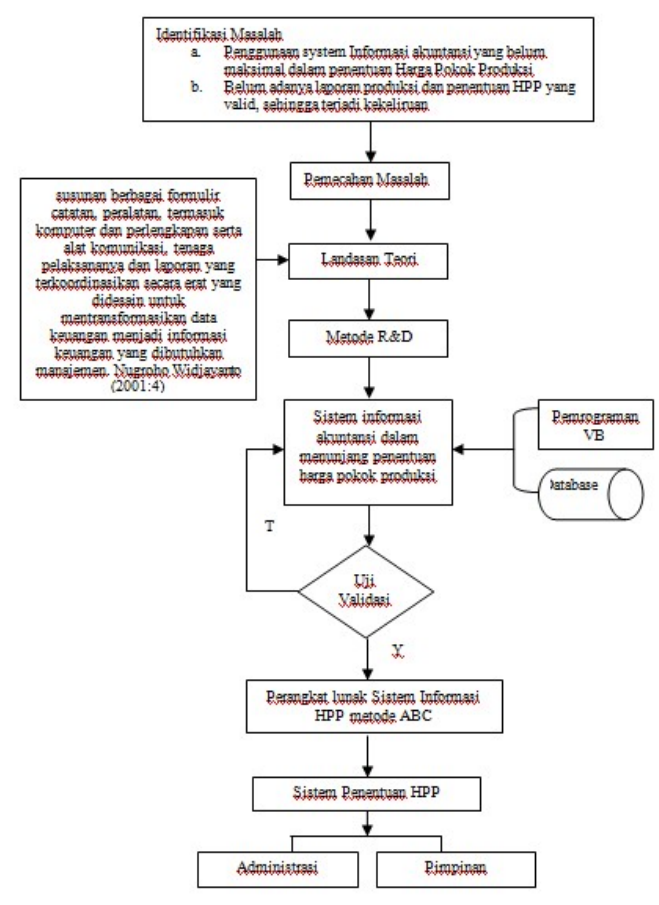

Gambar 3.2 Kerangka Berfikir 


\subsection{Flow of Document (Sistem Baru)}

Bagan alir dokumen menggambarkan model dari sistem informasi secara fisik yang melibatkan beberapa departemen di perusahaan tersebut.( Andri Kristanto, 2003)

Seperti halnya pada perusahaan ini, alur untuk sistem baru dirancang untuk membantu mendefenisikan kegiatan dalam penentuan harga pokok produksi agar lebih tersistem, dapat dilihat pada gambar 3.3

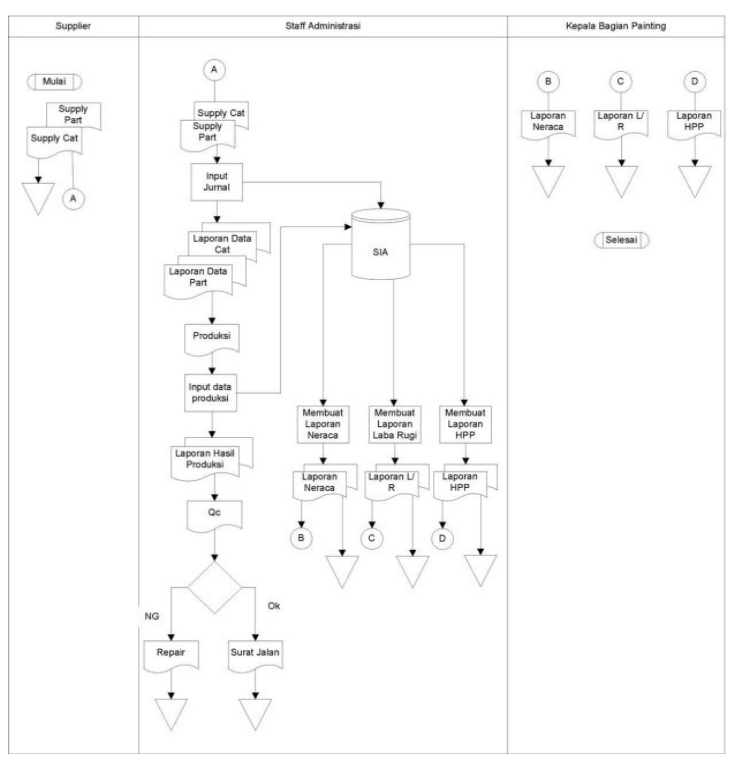

Gambar 3.3 Flow Of Document Baru

\subsection{Konteks Diagram}

Dalam konteks diagram gambar 3.4 dijelaskan bahwa pihak yang masuk kedalam sistem adalah administrasi atau bagian keuangan dan pimpinan.

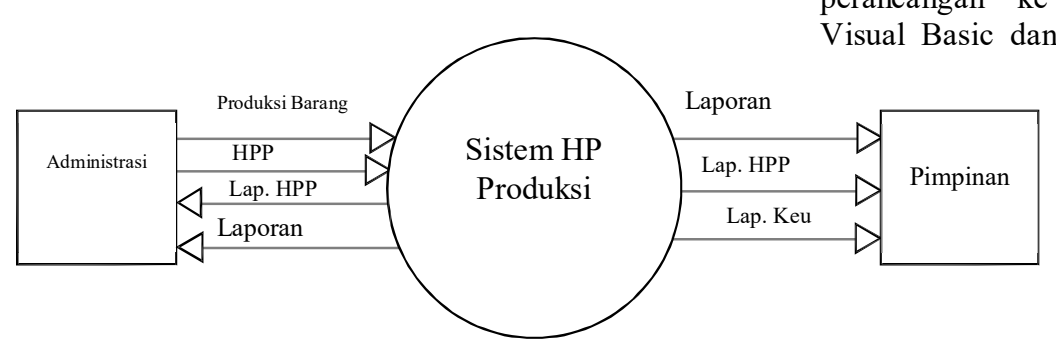

\section{Gambar 3.4 Konteks Diagram}

Pihak administrasi memberikan inputan berupa jenis produk barang dan harga pokok produksi, menerima dan mengarsip laporan harga pokok produksi dan laporan keuangan lainnya. Pihak pimpinan menerima laporan keseluruhan.

\subsection{Diagram level 1}

Pada diagram level 1 menjelaskan tentang turunan dari DFD level 0 yang merupakan cakupan dari input. Terdiri dari table cat, polosan, produksi cat, supplier, produksi polosan. Hal ini dapat dilihat dari gambar 3.5

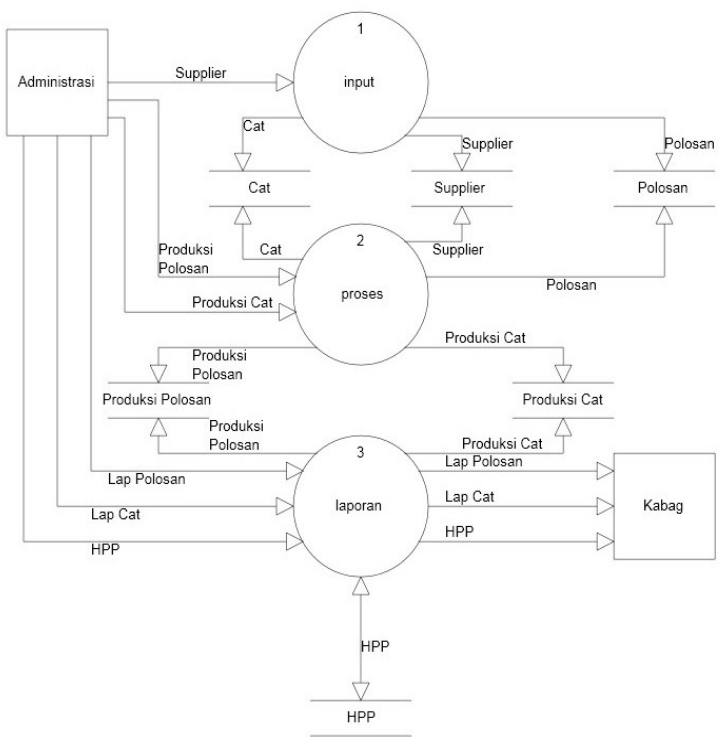

Gambar 3.5 DFD level 1

\section{Hasil dan Pembahasan}

Subyek yang diamati dalam penelitian ini adalah bagian produk komponen cat. Berdasarkan hasil penelitian yang telah dilakukan pada PT. Barokah sejahtera Semarang, maka diperoleh hasil akhir sebuah sistem yaitu sistem penentuan harga pokok produksi cat dengan metode Activity Based Costing (ABC).

Hasil ini didapat setelah menerapkan analisis dan perancangan ke dalam bahasa pemrograman Visual Basic dan Microsoft Access

\subsection{Hasil Pengembangan}

Tahapan yang diperlukan dalam perancangan dan pembuatan program yaitu menganalisa sistem yang yang sedang berjalan, mengidentifikasi dan mengevaluasi masalah-masalah yang terjadi serta kebutuhan yang diperlukan, sehingga dapat berjalan dengan baik.

\subsection{Hasil Laporan}

Hasil laporan program antara lain berupa form input harga pokok produksi (gambar 4.1) yang berfungsi untuk mecatat transaksi - transaksi produksi untuk menentukan harga pokok produksi. 
Sedangkan pada gambar 4.2 berupa laporan harga pokok produksi setiap periode

a. Input Harga Pokok Produksi

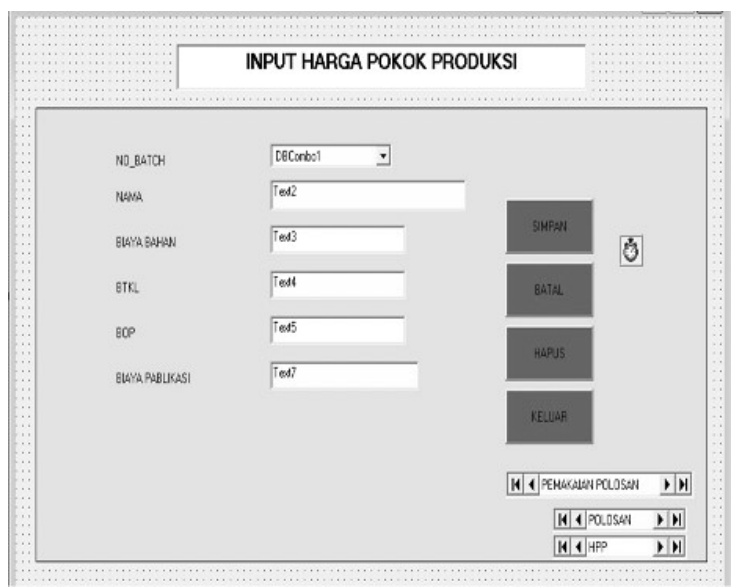

Gambar 4.1 Input Harga Pokok Produksi

b. Laporan Harga Pokok Produksi

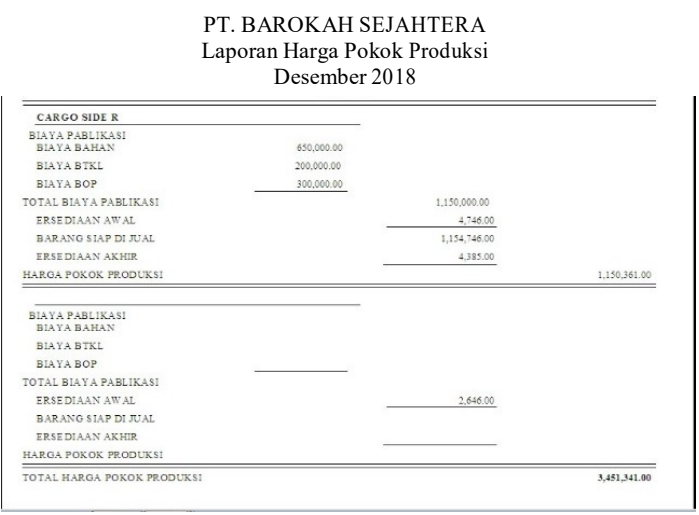

Gambar 4.2 Laporan Harga Pokok Produksi

5. Kesimpulan dan Saran

5.1 Kesimpulan

1. Penggunaan Sistem Informasi Akuntansi dapat membantu pihak manajemen dalam perhitungan harga pokok produksi sesuai dengan metode Activity Based Costing sehingga perhitungan lebih akurat dan cepat.

2. Dengan menggunakan sistem informasi akuntansi penentuan harga pokok produksi dengan metode activity based

3. Pihak Manajemen atau pimpinan dapat memonitor dan mengoreksi perubahan produksi dengan adanya laporan produksi setiap harinya.

4. Dengan dibuatkannya laporan laba rugi pemilik bisa mengetahui berapa keuntungan yang didapatkan perusahaan.

\subsection{Saran}

Saran yang dapat dikemukakan setelah pembuatan sistem informasi akuntansi perhitungan harga pokok produksi adalah sebagai berikut:

1. Sistem dapat dikembangkan dengan berbasis Web, sehingga pemesanan bisa diakses langsung melalui website.

2. Dengan diterapkannya sistem komputerisasi untuk perhitungan harga pokok produksi, maka perlu dilakukan pelatihan agar sistem berjalan dengan optimal.

3. Perlu adanya perawatan, supaya sistem bisa berjalan dengan baik dan melakukan backup data secara berkala untuk mengantisipasi kehilangan data.

\section{DAFTAR PUSTAKA}

Ahmad, Firdaus Dunia dan Wasilah Abdullah. 2012.Akuntansi Biaya. Jakarta: Salemba Empat

Andri Kristanto, 2003, Perancangan Sistem Informasi dan Aplikasinya, Penerbit :Gava Media, Jakarta.

Ahmad, Firdaus Dunia dan Wasilah Abdullah. 2012.Akuntansi Biaya.Jakarta:Salemba Empat

Armanto, Witjaksono. 2006. Akuntansi Biaya. Edisi pertama. Yogyakarta. Penerbit: Graha Ilmu.

Atmoko, E.H.2013. Program Akuntansi Beserta Manajemen Aset Menggunakan VB dan SQL Server. Jakarta: PT. Elex Media Komputindo

Borg, W.R. \& Gall, M.D. Gall. (1983). Educational Research: An Introduction,Fifth Edition. New York: Longman.

Budhi irawan, 2005, Jaringan komputer, Graha Ilmu, Yogyakarta

Date, C.J . 2005. Pengenalan Sistem Basisdata Jilid 2. Indeks. Jakarta.

Kieso, D. E., Weygandt, J. J., \& Warfield, T. D. (2010). Intermediate Accounting: IFRS Edition Volume 1. USA: John Wiley \& Sons.

Mulyadi. 2007. Akuntansi Biaya. Edisi 5. Yogyakarta : Aditya Medi

Sugiyono, (2008). Metode Penelitian Kunatitatif Kualitatif dan R\&D. Bandung Alfabeta

Widjajanto, Nugroho. 2001. Sistem Informasi Akuntansi. Erlangga: Jakarta 


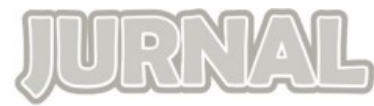

TEKNOLOGI INFORMASI DAN KOMUNIKASI 